\title{
Influence of interspecific interactions on avoidance response to contamination
}

\author{
Daniel C.V.R. Silva a,b,*, Cristiano V.M. Araújo ${ }^{c}$, Rodrigo J. Marassi ${ }^{\text {b,d }}$, Sheila Cardoso-Silva e , Morun B. Neto ${ }^{\mathrm{f}}$, \\ Gilmar C. Silva $^{\text {d }}$, Rui Ribeiro ${ }^{g}$, Flávio T. Silva ${ }^{\text {b, }}$ Teresa C.B. Paiva ${ }^{\text {b }}$, Marcelo L.M. Pompêo a \\ a Department of Ecology, University of São Paulo, São Paulo, Brazil \\ ${ }^{\mathrm{b}}$ Department of Biotechnology, Engineering School of Lorena, University of São Paulo, Lorena, São Paulo, Brazil \\ c Department of Ecology and Coastal Management, Institute of Marine Sciences of Andalusia (CSIC), Campus Río S. Pedro, 11510 Puerto Real, Cádiz, Spain \\ ${ }^{d}$ Department of Exact Sciences, School of Metallurgical and Industrial Engineering, UFF, Volta Redonda, Rio de Janeiro, Brazil \\ e Environmental Sciences Program, São Paulo State University - UNESP, Sorocaba campus, Avenida Três de Março 511, Alto da Boa Vista, Sorocaba, SP, 18087-180, Brazil \\ ${ }^{\mathrm{f}}$ Department of Basic and Environmental Sciences, Engineering School of Lorena, University of São Paulo, Lorena, São Paulo, Brazil \\ g Centre for Functional Ecology (CFE), Department of Life Sciences, University of Coimbra, Calçada Martim de Freitas, 3000-456 Coimbra, Portugal
}

\section{H I G H L I G H T S}

- The avoidance response of guppy and zebrafish to a copper gradient was evaluated.

- Contamination gradients were simulated using a non-forced exposure system.

- The effects of interspecific interactions on avoidance response was studied.

- Guppy and zebrafish avoided potentially toxic copper concentrations.

- The magnitude of avoidance by zebrafish was affected by the presence of guppy
G R A P H I C A L A B S T R A C T
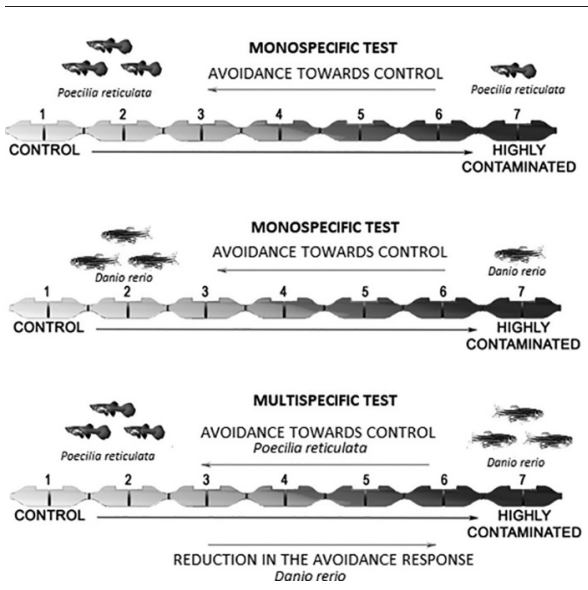

\section{A B S T R A C T}

An increasing number of studies have shown the ability of organisms to escape from toxic effects due to contamination, by moving spatially towards less contaminated habitats. However, this issue has been investigated in monospecific scenarios, without considering possible interactions between species during the contamination avoidance process. It is widely known that the spatial distribution of one species can be affected by another one, in different ways. Therefore, the main question addressed in the present study was as follows: Might interspecific interaction between the freshwater fish Danio rerio (zebrafish) and Poecilia reticulata (guppy) change their behavior patterns in terms of avoidance in the presence of a copper gradient? Zebrafish and guppies exposed to a copper gradient were tested for avoidance responses in a free-choice, non-forced, static, multicompartmented exposure system, using two distinct approaches: (1) monospecific tests, in which only one species was exposed to the copper gradient, at two different population densities; and (2) multispecific tests, in which both species were tested simultaneously. In the control (with no copper) monospecific tests, both species were randomly distributed; however, in the control multispecific test, $P$. reticulata tended to aggregate. In the

Interspecific interaction

Spatial distribution

\footnotetext{
* Corresponding author at: Department of Ecology, University of São Paulo, São Paulo, Brazil.

E-mail address: clemente.daniel@ib.usp.br (D.C.V.R. Silva).
} 
monospecific tests with a copper gradient, both species avoided copper in a similar way, with $\mathrm{AC}_{50}$ (concentration triggering avoidance in $50 \%$ of the exposed population) values between 15 and $18 \mu \mathrm{g} \cdot \mathrm{L}^{-1}$, irrespective of the population density. However, in the multispecific tests, $P$. reticulata displaced $D$. rerio to previously avoided copper levels, consequently increasing the $\mathrm{AC}_{50}$ of $D$. rerio to $75 \mu \mathrm{g} \cdot \mathrm{L}^{-1}$. This study shows the importance of understanding the interactions among species in contaminated areas, and the way that one species can prevent the avoidance behavior of another.

(C) 2018 Elsevier B.V. All rights reserved.

\section{Introduction}

The risks to organisms resulting from the exposure to contaminants are commonly related to damage caused to individuals, including lethal and sublethal effects (Martinez-Haro et al., 2015). Such damage is generally studied by means of ecotoxicological tests with forced exposure, involving the direct and continuous exposure of organisms to contaminants. Although less frequent, some earlier studies have indicated that organisms are able to detect and avoid contamination, thereby preventing them from suffering toxic effects (see review by Araújo et al., 2016). Evidence of avoidance to contamination was reported by Folmar (1976), who exposed the fish Salmo gairdneri (rainbow trout) to nine herbicides in a bi-compartmentalized system and observed how the fish preferred the clean region. Using a similar system, Gunn and Noakes (1986) evaluated the avoidance behavior of the fish Salvelinius fontinalis caused by low $\mathrm{pH}$ and addition of aluminum. In both studies, toxic effects at the individual level resulting from continuous exposure were prevented by the avoidance response to contamination.

Recently, a new approach using a free-choice, multicompartmented, non-forced system was proposed for use in ecotoxicological studies to assess how the spatial distribution of organisms is driven by contaminants (Lopes et al., 2004). The aim of this nonforced exposure approach is to simulate contamination gradients or patches, so that the effects are no longer measured using individuals, but instead using their spatial distribution. This approach expands the concept of environmental disturbance beyond the traditional one based exclusively on the toxicity (and bioaccumulation) at the organism level. Evidence of contamination-driven spatial displacement (avoidance response) in non-forced exposure systems has been described for many organisms including fish (Moreira-Santos et al., 2008; Araújo et al., 2014, 2018; Silva et al., 2017, 2018), amphibians (Araújo et al., 2014; Vasconcelos et al., 2016), and invertebrate species (Lopes et al., 2004; Araújo et al., 2016) exposed to different contaminants.

Although evidence of avoidance responses to contamination has been widely reported for many fish species (see review by Araújo et al., 2016), it is recognized that habitat selection processes may be conditioned by several factors other than contamination, such as temperature (Stehfest et al., 2017), pH (Fost and Ferreri, 2015), presence of predators (Scherer and Smee, 2016) and competitors (Dunlop et al., 2006), among others. In the natural environment, organisms are simultaneously exposed to several factors, so it is necessary to understand the extent to which contamination influences the habitat selection process, and the ways that these factors affect the avoidance response. For instance, Scherer and Mcnicol (1998) observed that Coregonus clupeaformis avoided exposure to $\mathrm{Cu}, \mathrm{Zn}$, and $\mathrm{Pb}$, but that the avoidance response was suppressed when the environment was shaded. Dunlop et al. (2006) found that the escape responses of Carassius auratus and Oncorhynchus mykiss to a harmful acute stimulus (electric shock) changed if the two species were present together. Araújo et al. (2016) observed that the habitat selection by tilapia (Oreochromis sp.) exposed to a contamination gradient in a non-forced exposure system was changed when food was offered, with the organisms moving to previously avoided areas in order to feed. These results indicate that while fish can avoid toxic effects by moving to less contaminated habitats, the presence of a more attractive factor (or one of immediate importance) in the potentially avoidable habitat can change the avoidance pattern.

Interspecific interaction might also affect the spatial distribution of organisms due to competition for food, space, or other factors intrinsic to each population (Begon et al., 2007). Studies have clearly demonstrated that the structure and functioning of communities can be greatly altered when different populations cohabit. For instance, the presence of Salmo gairdneri (rainbow trout) in a stream flume influenced the individual fitness of Luxilus coccogenis (warpaint shiner), in terms of prey capture success and feeding efficiency (Elkins and Grossman, 2014). The presence of the fish Carassius auratus forced the amphibian Ichthyosaura alpestris to remain longer in the terrestrial environment (Laurane et al., 2017). In a study performed in the North-Western Mediterranean Gulf, despite the overlap of three small pelagic fish (Sardina pilchardus, Engraulis encrasicolus, and Sprattus sprattus), the biomass of each species differed locally due to the influence of one over the others (Saraux et al., 2014).

In the presence of contaminants, changes in the patterns of interaction (such as competition and aggressiveness) among fish populations (Lingaraja et al., 1979; Clotfelter and Rodriguez, 2006) are expected to occur. Therefore, considering that (i) fish can avoid contamination by moving spatially towards less contaminated habitats, and (ii) contamination can affect the behavior of fish in terms of aggressiveness, competition, and spatial displacement, the main question addressed in the present study was: Might interspecific interaction between the freshwater fish Danio rerio (zebrafish) and Poecilia reticulata (guppy) change their patterns of avoidance to contamination? The goal of the present study was to assess if the avoidance responses of these two fish populations exposed to a contamination gradient might be affected by interspecific interactions. It was expected that the less aggressive species would be displaced towards previously avoided contaminated habitats. Copper $\left(\mathrm{Cu}^{2+}\right)$ was selected as a test contaminant as it is an avoidable pollutant for fish (Moreira-Santos et al., 2008; Araújo et al., 2015) and produces toxic effects such as chemosensory deprivation (McIntyre et al., 2008), changes in gene expression (Craig et al., 2010), feeding inhibition (Abdel-Moneim et al., 2015), effects on the swimming performance of larvae (Acosta et al., 2016), morphological and metabolic alterations (Chatterjee et al., 2016), and changes in the surfaces of the gills (Fu et al., 2016). P. reticulata and D. rerio were selected as test organisms because they (i) are easy to cultivate, (ii) are widely used as model organisms in the fields of ecology, evolution, and ethology, and (iii) have already been shown to spatially avoid chemical contamination (Moreira-Santos et al., 2008; Araújo et al., 2014, 2014; Silva et al., 2017).

\section{Materials and methods}

\subsection{Test organisms}

Individuals of the fish $P$. reticulata and $D$. rerio ( 2 to 3 months old and with total length between 1.0 and $1.5 \mathrm{~cm}$ ) were obtained from the São Paulo Agency of Agribusiness and Technology (Pindamonhangaba, Brazil) and the company Power Fish (Rio de Janeiro, Brazil), respectively. The use of the fish was approved by the Ethics Committee on the Use of Animals (Institute of Biosciences, University of São Paulo; protocol \#236/2015). The organisms were acclimated under laboratory conditions (at the Ecotoxicology Laboratory of the Lorena School of 
Engineering (EEL-USP), Department of Biotechnology (DEBIQ), Lorena, São Paulo, Brazil) for at least one week prior to the tests, following OECD guidelines (OECD, 2000). No mortality was observed during the culture period. Fish were kept in $60 \mathrm{~L}$ aquaria filled with activated charcoal-filtered well water. The cultures were constantly aerated using an air diffuser and the water was renewed by $30 \%$ every week. The animals were fed daily, ad libitum, with commercial fish food flakes (Tetramin $\left.{ }^{\circledR}\right)$, until $24 \mathrm{~h}$ prior to the experiments. The $\mathrm{pH}(7.0 \pm 0.5)$, conductivity $\left(120 \pm 20 \mu \mathrm{S} \cdot \mathrm{cm}^{-1}\right)$, and dissolved oxygen content (6.4 $\pm 0.4 \mathrm{mg} \cdot \mathrm{L}^{-1}$ ) of the culture water were monitored on a daily basis. Natural light was provided in the room, without direct exposure to the sun (natural photoperiod of around 12:12 h light:dark), and the mean temperature was $23 \pm 2{ }^{\circ} \mathrm{C}$. Before the avoidance experiments, some organisms were selected and tested for the sensitivity of the fish population by performing toxicity tests using potassium dichromate $\left(\mathrm{K}_{2} \mathrm{Cr}_{2} \mathrm{O}_{7}\right)$ as a reference substance, at concentrations ranging from 10 to $300 \mathrm{mg} \cdot \mathrm{L}^{-1}$, following the OECD guidelines (OECD, 2000). The $\mathrm{LC}_{50}$ values (mean \pm standard deviation; $\mathrm{n}=3$ ) were $41.66 \pm$ $14.17 \mathrm{mg} \cdot \mathrm{L}^{-1}$ (P. reticulata) and $127.3 \pm 19.53 \mathrm{mg} \cdot \mathrm{L}^{-1}$ (D. rerio), which were considered acceptable since they were within the upper and lower limits of the control charts for these species, provided by the Ecotoxicology Laboratory of the Lorena School of Engineering (21.0 to $63.8 \mathrm{mg} \cdot \mathrm{L}^{-1}$ and 75.8 to $167.0 \mathrm{mg} \cdot \mathrm{L}^{-1}$, respectively).

\subsection{Contaminant solution preparation and chemical analysis}

The stock copper solution used in the avoidance tests was prepared by dissolving metallic copper powder (99.99\%, VETEC/Sigma) in sulfuric acid $\left(\mathrm{H}_{2} \mathrm{SO}_{4}\right)$ (95-99\%, VETEC/Sigma). All the concentrations employed were prepared with ultrapure water (resistivity $18.2 \mathrm{M} \Omega \mathrm{cm}$ ). Controls were prepared with sulfuric acid, in the same proportions as the copper treatments. The copper concentrations were checked at the end of all the tests, which were performed in triplicate $(n=3)$. The samples retrieved after the tests were stored at $4{ }^{\circ} \mathrm{C}$, in the dark, for a maximum of 1 week. For transport to the analysis laboratory, the samples were cooled in thermally insulated packages. The copper concentrations were determined at the Chemical Analysis Laboratory of Federal Fluminense University (UFF), in Volta Redonda, Rio de Janeiro, using a Varian 55B flame atomic absorption spectrometer. The instrument was operated with an air/acetylene flame, at $324.8 \mathrm{~nm}$, with the flame, wavelength, and sample aspiration rate adjusted according to the manufacturer's recommendations. The procedures used for the standard curve and the analyses followed the protocol of the Standard Methods for the Examination of Water and Wastewater (APHA, 2012). A stock copper standard solution $\left(100 \mathrm{mg} \cdot \mathrm{L}^{-1}\right)$ was diluted to obtain the concentration range from 0 to $1000 \mu \mathrm{g} \cdot \mathrm{L}^{-1}$. The linear equation of the calibration curve was $\mathrm{y}=9.5 \times 10^{-5} \mathrm{x}-6.4 \times 10^{-4}\left(\mathrm{r}^{2}=0.999\right)$.

\subsection{Non-forced exposure system}

Non-forced avoidance tests were performed in a free-choice static exposure system composed of seven interconnected chambers (Fig. 1; Araújo et al., 2014) constructed from borosilicate glass bottles, handcrafted in a high temperature furnace at $600{ }^{\circ} \mathrm{C}$. The chambers were connected using sections of nontoxic transparent silicone hose. The system had a total length of $105 \mathrm{~cm}$ and a total volume of $980 \mathrm{~mL}$, with each compartment having a volume of $140 \mathrm{~mL}$. For the tests, the chambers were filled with $125 \mathrm{~mL}$ of water containing copper at different concentrations, so that the total system volume was $875 \mathrm{~mL}$.

\subsection{Avoidance tests}

Two distinct approaches were adopted in the avoidance tests: (1) monospecific tests, in which only one species was introduced into the system, at two different population densities (one or two individuals per chamber), and (2) multispecific tests, in which both species

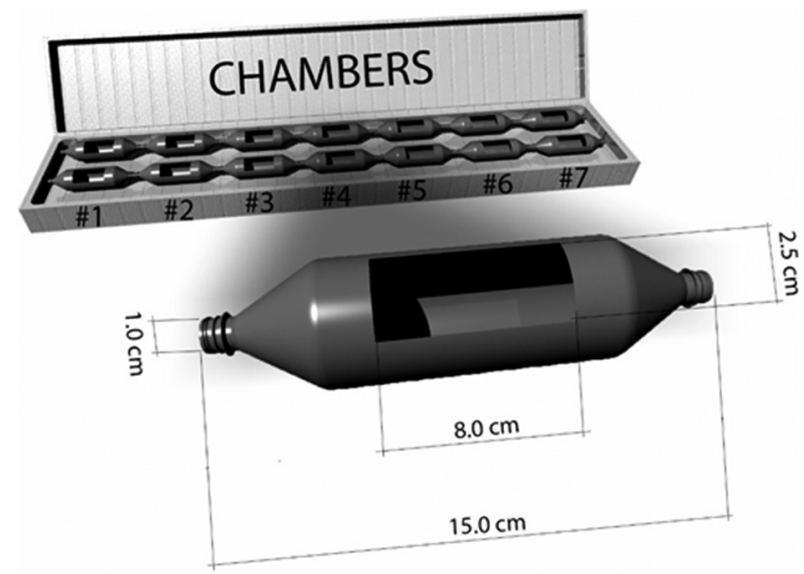

Fig. 1. Schematic diagram of the static multi-compartmented non-forced avoidance test system, highlighting one of the seven compartments.

were tested simultaneously in the system. The two different densities were employed in order to ensure that the copper avoidance response would not be affected by the population density.

Firstly, control distribution tests in which the system was filled with $875 \mathrm{~mL}$ ( $125 \mathrm{~mL}^{*}$ seven chambers) of culture water (with no contamination) were conducted to confirm that the fish did not have preference for any of the seven chambers. In the monospecific approach, 14 fish were used per system ( 2 fish in each chamber), while in the multispecific approach, 14 fish were used in total per system, with 7 organisms of each species being introduced into the same system (one fish of each species per chamber).

After checking the spatial distribution of the fish in the absence of contamination, avoidance tests were carried out with a copper gradient. The monospecific tests were performed with 7 and 14 fish per system, while in the multispecific approach, 14 fish ( 7 fish of each species per system) were employed. In each system, the same copper gradient was prepared from a $100,000 \mu \mathrm{g} \cdot \mathrm{L}^{-1}$ stock solution, with nominal concentrations in the chambers of $0,10,20,30,40,55$, and $70 \mu \mathrm{g} \cdot \mathrm{L}^{-1}$, hence forming a copper gradient. Prior to introducing the solutions into the chambers, plasticine plugs wrapped in PVC were inserted between adjacent chambers, using a clamp, hence blocking the connections between them and preventing mixing of the concentrations. After filling the system with the different concentration solutions, the fish were introduced and the plugs were removed.

All the tests (control with no gradient and avoidance with copper gradient) were performed in a dark room, at $23 \pm 2{ }^{\circ} \mathrm{C}$. Observations were made every 30 min during $3 \mathrm{~h}$ exposure (at $0.5,1.0,1.5,2.0,2.5$, and $3.0 \mathrm{~h}$ ), using a red light to prevent interference due to the presence of the observer. The organisms were not fed during the tests. All the tests were performed in triplicate. At the end of the tests, plugs were inserted between adjacent chambers to close the connections, and samples were then taken for determination of the final copper concentrations.

\subsection{Statistical analyses}

In the non-forced approach, a mixed-design ANOVA was employed to evaluate the distributions (in \%, arcsine transformed) of the fish in the control (using only culture water) and avoidance (with copper gradient) monospecific and multispecific tests. In this analysis, time was treated as a within-subjects factor (repeated measurements), while chamber was treated as a between-subjects factor. The sphericity of the repeated measurements was evaluated using Mauchly's test; in the case of noncompliance (with the variances of the differences not being equal: $p<0.05$ ), the Greenhouse-Geisser correction for degrees of freedom was applied. When statistically significant differences ( $\mathrm{p}<$ 
0.05 ) were observed for time or compartment, pairwise comparisons were performed using the Bonferroni post-hoc test. In the case of the observation times, if the results of the repeated measurements were not significant $(p>0.05)$, the fish distribution data to be represented in the graphs were pooled, considering the means from the six times $(0.5,1.0,1.5,2.0,2.5$, and $3.0 \mathrm{~h})$.

In the avoidance tests with a copper gradient, calculation of the avoidance response (in \%) was based on the method described by Moreira-Santos et al. (2008). Firstly, the number of avoiders was determined using the following equation: Avoiders $=N_{E}-N_{O}$, where $N_{E}$ is the number of expected organisms and $N_{O}$ is the number of observed organisms. For the compartment with the highest copper concentration (the seventh chamber), $N_{E}$ was equal to the number of fish introduced into the chamber at the beginning of the test, since it was not expected that the organisms would move from the lower concentrations to that chamber. For the remaining chambers, $N_{E}$ included the organisms initially introduced into the chamber, plus the organisms introduced into the adjacent chamber with higher concentration. For instance, if two fish were introduced at the beginning of the experiment, $N_{E}$ for the sixth chamber was equal to 4 , because it considered the two organisms introduced into the sixth chamber and the two organisms introduced into the seventh chamber (these two fish were expected to move to lower concentrations). The calculation of $N_{O}$ considered the organisms recorded in a given concentration and those recorded in higher concentrations. For instance, for the seventh chamber, $N_{O}$ represented the organisms found in that chamber, while for the sixth chamber, $N_{O}$ represented the organisms recorded in both the sixth and the seventh chambers. This reasoning was based on the fact that organisms able to inhabit concentrations higher (e.g., the seventh chamber) than that to be studied (e.g., the sixth chamber) were not considered avoiders. As the control chamber contained only culture water, avoidance was not expected $\left(N_{E}-N_{O}=0\right)$. Finally, the avoidance percentage for each chamber was calculated as follows: (Avoiders $\left./ N_{E}\right) * 100$. From the avoidance percentages, the $\mathrm{AC}_{20}, \mathrm{AC}_{50}$, and $\mathrm{AC}_{80}$ values (the copper concentrations causing avoidance in 20,50 , and $80 \%$ of the exposed population, respectively) and their corresponding confidence intervals (CI) were calculated using PriProbit software (Sakuma, 1998).

\section{Results}

\subsection{Control of fish population distributions}

The distributions of fish in the control tests (using culture water) were analyzed for the monospecific (14 fish per system) and multispecific ( 7 fish of each species, totaling 14 fish per system) experiments, in order to determine whether the distributions occurred in a random fashion (Fig. 2). In the monospecific tests with $P$. reticulata, the fish distribution was random (see details in Tables S1, S2a, S2b, and S2c of the Supplementary material), with no statistically significant differences in the percentages of organisms among the chambers $\left(F_{6,14}\right.$ $=0.355, \mathrm{p}=0.895)$. The repeated measurements indicated that the movement of the organisms in the system did not vary with time $\left(F_{2.857,40.005}=0.062\right.$ after Greenhouse-Geisser correction, $\left.\mathrm{p}=0.976\right)$. The interaction between the two factors (time and chamber) was not statistically significant $\left(F_{17.145,40.005}=1.069\right.$ after Greenhouse-Geisser correction, $\mathrm{p}=0.404$ ). The same random distribution pattern was observed for $D$. rerio in the control test (time: $F_{5,70}=0.129, p=0.985$; time and chambers: $\mathrm{F}_{30,70}=1.018, \mathrm{p}=0.461$; chambers: $\mathrm{F}_{6,14}=$ $0.312, p=0.920$; see details in Tables S3, S4a, S4b, and S4c of the Supplementary material).

In the multispecific tests (see details in Table S5 of the Supplementary material), the data were treated considering the species individually ( 7 fish) and in combination as a community with two populations (14 fish). In the case of P. reticulata, the fish distribution was not totally random, with statistically significant differences in the percentages of organisms among the chambers $\left(F_{6,14}=3.320, p=0.030\right)$, particularly between chamber 1 and chamber 7 (Bonferroni test). The repeated measurements indicated that the movement of organisms in the system did not vary with time $\left(F_{5,70}=0.038, p=0.999\right)$. The interaction between the two factors (time and chamber) was not statistically significant $\left(\mathrm{F}_{30,70}=1.091, \mathrm{p}=0.373\right.$ ) (see details in Tables S6a, S6b, and S6c of the Supplementary material). For $D$. rerio, the fish distribution was random and the repeated measurements indicated that the movement of the organisms in the system did not vary with time or according to the two factors (time and chamber) (chambers: $\mathrm{F}_{6,14}=0.667, \mathrm{p}=$ 0.678; time: $\mathrm{F}_{3.220,45.077}=0.055$ after Greenhouse-Geisser correction,

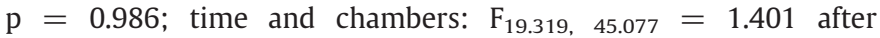
Greenhouse-Geisser correction, $\mathrm{p}=0.174$; see details in Tables S7a, S7b, and S7c of the Supplementary material).

Considering the distribution of both species together (14 fish per system), there was no statistically significant difference among the chambers $\left(F_{6,14}=1.731, p=0.186\right)$ and the repeated measurements indicated that the movement of the organisms in the system did not vary with time or considering the interactions of both factors (time and chamber) (time: $F_{5,70}=0.050, p=0.998$; time and chambers: $\mathrm{F}_{30,70}=1.126, \mathrm{p}=0.335$; see details in Tables S8a, S8b, and S8c of the Supplementary material).

\subsection{Avoidance response to copper using the monospecific approach}

Two distinct scenarios (with 7 and 14 fish per system) were analyzed in the monospecific tests with a copper contamination gradient, in order to evaluate the effect of the population density on the distribution of the organisms. For P. reticulata (Tables S9, S10a, S10b, and S10c of
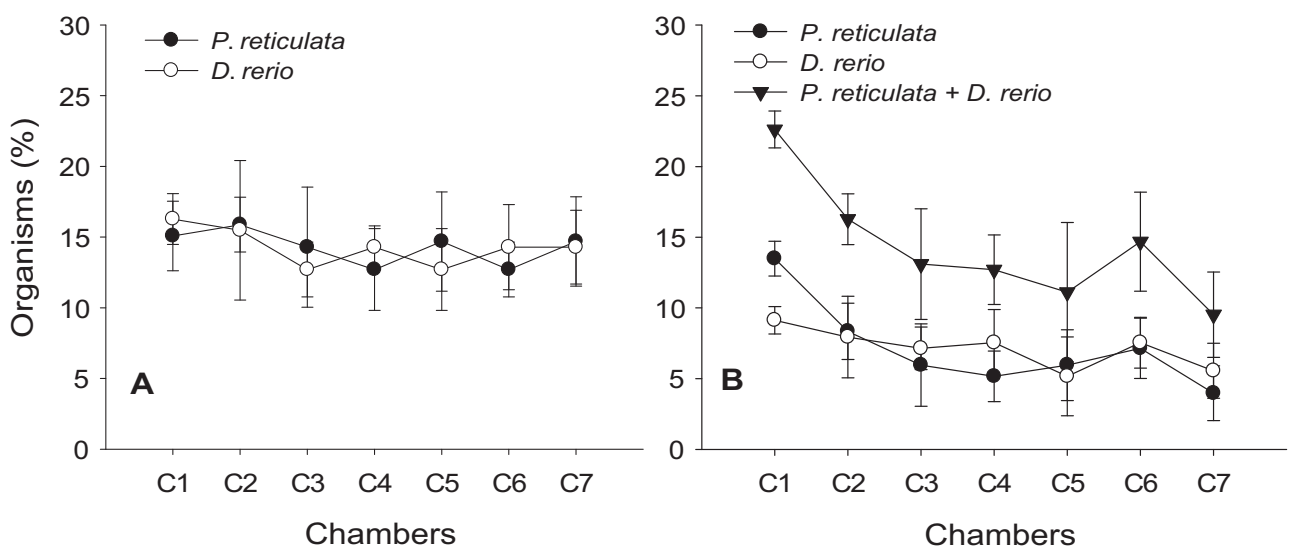

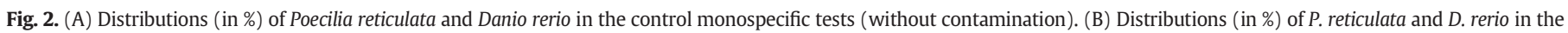
control multispecific tests (without contamination). The lines show the mean distributions of the fish species individually and in combination. 

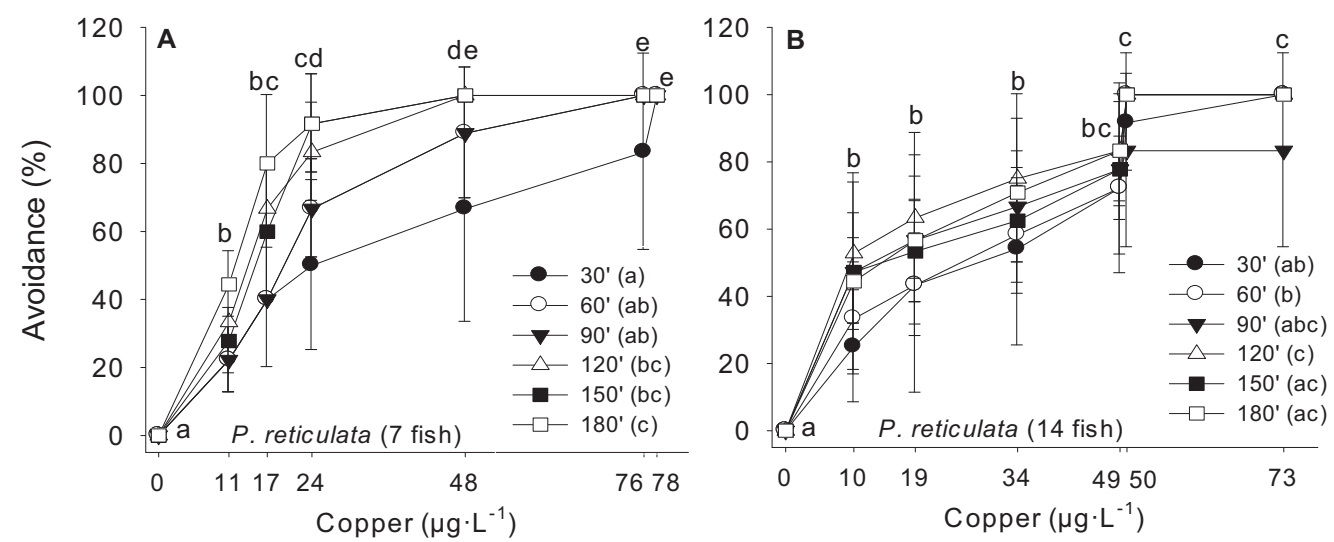

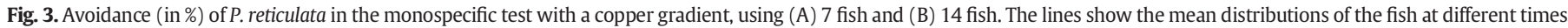

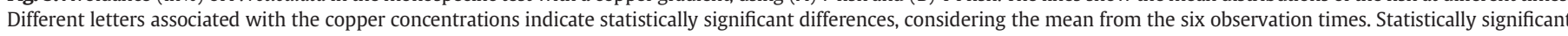
differences among the times are shown by different letters in the legends.

the Supplementary material), in the first scenario ( 7 fish), the distribution of the organisms was influenced by the different copper concentrations $\left(F_{6,14}=92.129, \mathrm{p}<0.001\right)$ and time $\left(F_{2.537,35.520}=10.313\right.$ after Greenhouse-Geisser correction, $\mathrm{p}<0.001$ ) (Fig. 3-A). However, for the interaction of the two fixed factors (time and chamber), there was no statistically significant effect $\left(F_{15.223,35.520}=1.572\right.$ after GreenhouseGeisser correction, $\mathrm{p}=0.131$ ). The avoidance means and standard deviations (in \%, considering the six observation times) for each concentration $\left(0,11,17,24,48,76\right.$, and $\left.78 \mu \mathrm{g} \cdot \mathrm{L}^{-1}\right)$ were $0.0,29.0,54.0,75.0,91.0$, 97.0 , and 100.0, respectively. In the second scenario (14 fish), only the concentrations influenced the distribution $\left(\mathrm{F}_{6,14}=30.046, \mathrm{p}<0.001\right)$. For time and the interaction of the two factors (time and chamber) there were no statistically significant effects (time: $F_{2.160,30.241}=$ 3.230 after Greenhouse-Geisser correction, $\mathrm{p}=0.050$; time and chamber: $\mathrm{F}_{12.961,30.241}=0.839$ after Greenhouse-Geisser correction, $\mathrm{p}=$ 0.618) (Fig. 3-B; Tables S11, S12a, S12b, and S12c of the Supplementary material). Irrespective of the population density, the organisms tended to avoid the contaminated chambers, moving towards the control chamber. The avoidance means and standard deviations (in \%, considering the six observation times) for each effective copper concentration $\left(0,10,19,34,49,50\right.$, and $\left.73 \mu \mathrm{g} \cdot \mathrm{L}^{-1}\right)$ were $0.0,41.67,52.78,64.58$, $77.78,95.83$, and 97.22 , respectively.

For the tests with $D$. rerio, in both scenarios (with 7 and 14 fish per system) the distributions were determined by the concentration gradient, with the organisms tending to migrate to less contaminated areas (Figs. 4-A and B; Supplementary material Tables S13, S14a, S14b, and
S14c ( 7 fish), and S15, S16a, S16b, and S16c (14 fish)). D. rerio showed similar gradient-dependent distribution patterns in both scenarios, with the concentration and time (for 7 fish only) being statistically significant factors (for 7 fish: chambers: $\mathrm{F}_{6,14}=510.238, \mathrm{p}<0.001$; time: $\mathrm{F}_{2.041,28.574}=5.494$ after Greenhouse-Geisser correction, $\mathrm{p}<0.05$; time and chambers: $F_{12.246,28.574}=1.073$ after Greenhouse-Geisser correction, $\mathrm{p}=0.417$; for 14 fish: chambers: $\mathrm{F}_{6,14}=1957.549, \mathrm{p}<0.001$; time: $F_{2.082,29.150}=3.034$ after Greenhouse-Geisser correction, $\mathrm{p}=$ 0.06; time and chambers: $F_{12.493,29.150}=0.456$ after GreenhouseGeisser correction, $\mathrm{p}=0.928$ ).

The avoidance mean and standard deviation values (in \%, considering the six observation times) for each effective copper concentration $\left(0,10,18,21,27,50\right.$, and $\left.67 \mu \mathrm{g} \cdot \mathrm{L}^{-1}\right)$ were $0.0,22.22,43.33,65.28$, $87.04,97.22$, and 100.0 , respectively ( 7 fish), and (for effective copper concentrations of $0,11,14,21,31,43$, and $\left.64 \mu \mathrm{g} \cdot \mathrm{L}^{-1}\right) 0.0,22.69$, $36.11,50.69,67.59,98.61$, and 100.0 , respectively ( 14 fish).

\subsection{Avoidance response to copper using the multispecific approach}

The data from the multispecific tests were treated according to species and for the community, merging the data for both species (Tables S17 to S20, Supplementary material). In all the scenarios and for both species, only the concentrations/chambers presented statistically significant effects in terms of the fish distributions ( $P$. reticulata ( 7 fish): chambers: $F_{6,14}=19.129, p<0.0001$; time: $F_{1.819,25.463}=$ 1.533 after Greenhouse-Geisser correction, $\mathrm{p}=0.235$; time and
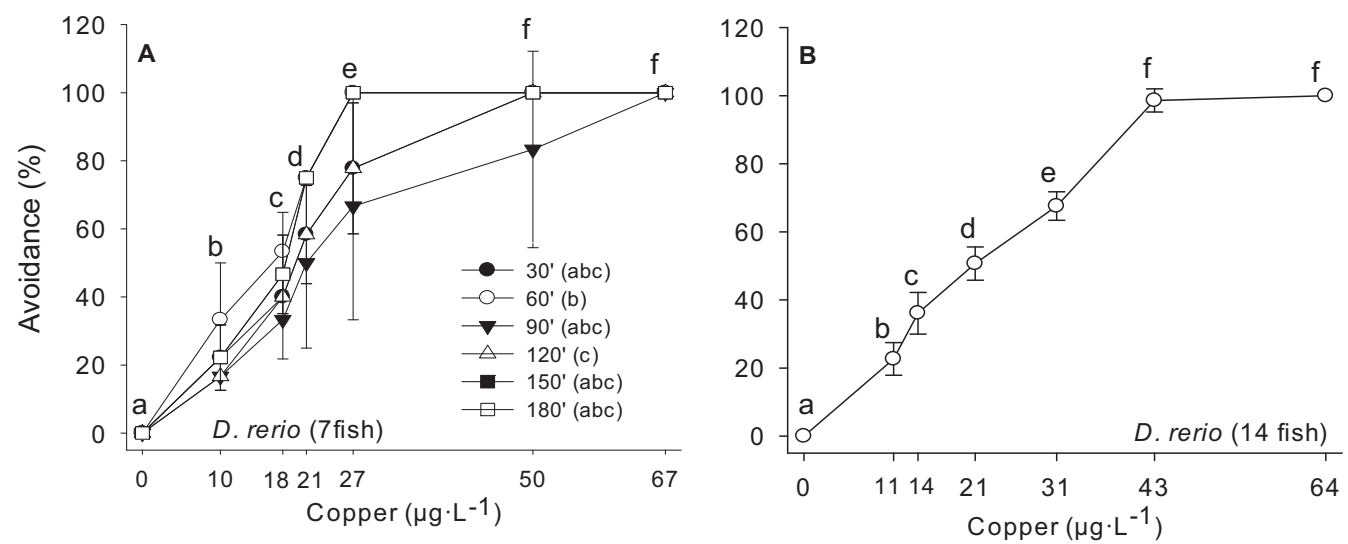

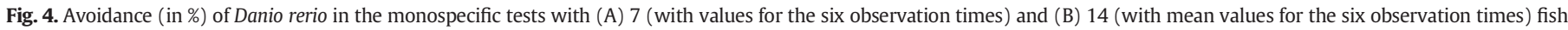

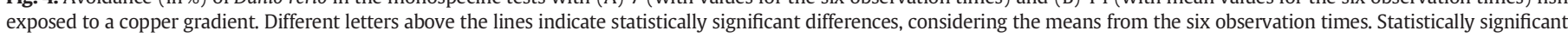
differences among the times are shown by different letters in the legend. 


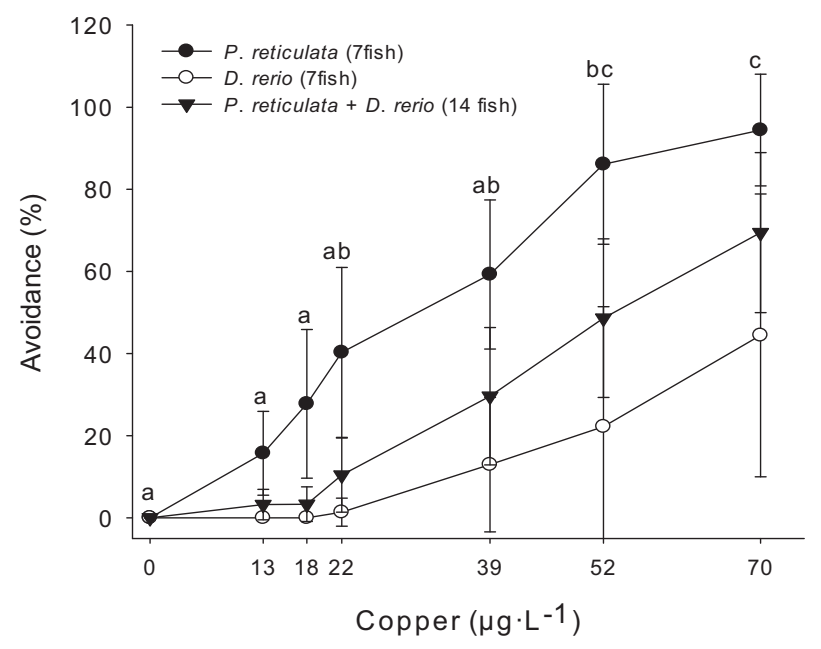

Fig. 5. Mean avoidance values (in \%) from the six observation times for Poecilia reticulata and Danio rerio, individually and in combination, in the multispecific test with 14 fish exposed to a copper gradient. Different letters indicate statistically significant differences ( $P$. reticulata $+D$. rerio).

chambers: $\mathrm{F}_{10.913,25.463}=0.718$ after Greenhouse-Geisser correction, $\mathrm{p}$ $=0.710$. D. rerio ( 7 fish): chambers: $\mathrm{F}_{6,14}=3.533, \mathrm{p}<0.05$ (in this case, although ANOVA detected differences, they were not discriminated by the post-hoc test); time: $F_{2.680,37.522}=1.965$ after GreenhouseGeisser correction, $\mathrm{p}=0.142$; time and chambers: $\mathrm{F}_{16.081}, 37.552=$ 1.023 after Greenhouse-Geisser correction, $\mathrm{p}=0.456$. P. reticulata and D. rerio ( 14 fish): chambers: $F_{6,14}=11.435, p<0.0001$; time: $F_{5,70}$ $=2.084, \mathrm{p}=0.078$; time and chambers: $\left.\mathrm{F}_{30,70}=1.048, \mathrm{p}=0.423\right)$.

For $P$. reticulata, the avoidance mean and standard deviation values (in \%, considering the six observation times) for each effective copper concentration $\left(0,13,18,22,39,52\right.$, and $\left.70 \mu \mathrm{g} \cdot \mathrm{L}^{-1}\right)$ were $0.0,15.74$, $27.78,40.28,59.26,86.11$, and 94.44 , respectively. For $D$. rerio, the values were $0.0,0.0,0.0,1.39,12.96,22.22$, and 44.44 , respectively. For the combined population ( $P$. reticulata $+D$. rerio), the values were 0.0 , 3.24, 3.33, 10.42, 29.63, 48.61, and 69.44, respectively (Fig. 5).

\subsection{Effective concentrations: $A C_{20}, A C_{50}$, and $A C_{80}$}

Table 1 shows the copper concentrations that caused avoidance in 20,50 , and $80 \%$ of the fish populations $\left(\mathrm{AC}_{20}, \mathrm{AC}_{50}\right.$, and $\left.\mathrm{AC}_{80}\right)$ in the monospecific and multispecific tests, together with the corresponding confidence intervals. For both species, the avoidance responses $\left(A C_{x}\right.$ values) for the different population densities ( 7 or 14 fish) were very similar. In the case of the multispecific tests, the most evident feature was the much lower avoidance of $D$. rerio exposed to copper, with decreases in avoidance percentages of 4.27 and 4.06 times, comparing the $\mathrm{AC}_{20}$ (14 fish) and $\mathrm{AC}_{50}$ (14 fish) values of the monospecific test with the $A_{20}$ and $A C_{50}$ values of the multispecific test, respectively.

\section{Discussion}

\subsection{Control distribution in the absence of a contamination gradient}

In the monospecific tests in the absence of contamination, the distribution of the organisms within the system was random, with no preference for any compartment. This confirmed that there were no external interferences (such as light or noise) or interactions among the organisms affecting the displacement of the organisms in the system. In other studies using the non-forced exposure system, similar behavior was observed for the fish species D. rerio (Moreira-Santos et al., 2008), Rachycentron canadum (Araújo et al., 2015), Oreochromis sp. (Araújo et al., 2016), and P. reticulata (Silva et al., 2017, 2018).

In the multispecific tests without a contamination gradient, $P$. reticulata showed a tendency to aggregate, which was not observed for $D$. rerio. Since this tendency was not observed in the monospecific tests, the response of $P$. reticulata was probably the result of interspecific interaction. This type of interaction has been reported previously. For example, in a study conducted along a stretch of the Au Sable River (Michigan, USA) with two species of trout, brook trout (Salvelinus fontinalis) and brown trout (Salmo trutta), the brown trout were forced to move to other resting areas when the brook trout were present, due to competition for space (Fausch and White, 1981). According to Chapman (1966), fish have minimum spatial requirements that are related to the size of the individual fish, visual isolation, and maintenance of distance, which are mediated by psychological and physiological factors associated with food. Stream fish seem to exhibit reduced aggression and greater tolerance of contemporaries at closer range, if food is temporarily superabundant. It is therefore likely that the gregarious behavior of $P$. reticulata could be explained by competition for space.

Several studies have identified aggregation/exploitation behavioral patterns and shoal formation in populations of $P$. reticulata and D. rerio. Seghers and Magurran (1995) showed that changes in behavior can be attributed to variation in the predation regime or the presence of another species. For example, guppies that co-occur with the pike cichlid Crenicichla alta spend more time shoaling and form larger shoals than their counterparts from low-risk habitats (without other species). Chapman et al. (2008) found that guppy populations vary markedly in their tendency to form shoals, with an important factor being individual experience during early ontogeny, which can lead to the formation of larger or smaller shoals in the adult phase. The scientific literature recognizes two main aggregation patterns: shoals (aggregations of individuals that remain close to each other) and schools (aggregations of aligned, or polarized, individuals). D. rerio tends to form small shoals (Gimeno et al., 2016). Buske and Gerlai (2011) analyzed the agedependent changes of shoaling in zebrafish and found a significant increase of shoaling with age (with decreased distance between shoal members). Under some conditions, both species studied here can form shoals. This was observed for $P$. reticulata in the multispecific control assay, but not in the tests using the fish species separately, when the individuals were randomly distributed.

Table 1

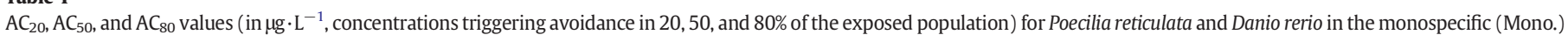
and multispecific (Multi.) tests.

\begin{tabular}{|c|c|c|c|c|c|}
\hline Test & Species & Density $^{\mathrm{a}}$ & $\mathrm{AC}_{20}$ & $\mathrm{AC}_{50}$ & $\mathrm{AC}_{80}$ \\
\hline \multirow{4}{*}{ Mono. } & P. reticulata & 7 & $8.5(6.6-10.3)$ & $15.9(13.7-18.0)$ & $29.6(26.1-34.3)$ \\
\hline & & 14 & $6.1(0.70-11.6)$ & $15.5(5.8-23.1)$ & $39.1(26.6-81.9)$ \\
\hline & D. rerio & 7 & $10.6(7.7-12.7)$ & $16.7(14.2-19.1)$ & $26.6(23.0-32.6)$ \\
\hline & & 14 & $11.2(7.0-14.4)$ & $18.7(14.5-22.9)$ & $31.0(25.0-44.8)$ \\
\hline \multirow[t]{3}{*}{ Multi. } & P. reticulata & 7 & $15.2(11.9-17.9)$ & $27.1(23.7-30.9)$ & $48.4(41.3-60.4)$ \\
\hline & D. rerio & 7 & $48.0(45.4-50.6)$ & $75.9(70.6-83.2)$ & $119.9(105.9-141.4)$ \\
\hline & Both populations & 14 & $30.2(27.2-32.9)$ & $52.6(48.1-58.3)$ & $91.6(79.6-110.2)$ \\
\hline
\end{tabular}

\footnotetext{
a Number of individuals of a species in the system.
} 


\subsection{Avoidance response to a copper gradient: monospecific tests}

The avoidance responses for the same species at different densities ( 7 or 14 fish) were very similar. Therefore, the densities that were tested did not seem to influence the avoidance behavior. Comparison of the responses of the two fish species in the monospecific tests showed that $P$. reticulata was more sensitive than $D$. rerio. The greatest difference between the two species occurred using $10 \mu \mathrm{g} \cdot \mathrm{L}^{-1}$ (P. reticulata) and 11 $\mu \mathrm{g} \cdot \mathrm{L}^{-1}$ (D. rerio) of copper and 14 organisms, where the mean guppy avoidance percentage during the test (41.67\%) was almost 2-fold higher than the value obtained for the zebrafish (22.69\%). This difference became less pronounced as the copper concentrations increased. Similar avoidance patterns have been reported in other studies with guppy and zebrafish exposed to different contaminants. Araújo et al. (2014) exposed zebrafish to a fungicide (pyrimethanil) gradient, while Silva et al. $(2017,2018)$ analyzed the escape response of $P$. reticulata exposed to the compounds triclosan and bisphenol. In those cases, the organisms were able to detect the compounds present at environmentally relevant concentrations and moved to less contaminated areas. The zebrafish were more susceptible to copper and were capable of identifying the contamination risk, moving to less contaminated regions in order to reduce the exposure to high concentrations and minimize potential toxic effects. Moreira-Santos et al. (2008) exposed D. rerio to copper in monospecific tests and found dose/avoidance responses very similar to those observed here, with $\mathrm{AC}_{50}$ values ranging from 16 to $22 \mu \mathrm{g} \cdot \mathrm{L}^{-1}$, compared to $\mathrm{AC}_{50}$ of $\sim 16 \mu \mathrm{g} \cdot \mathrm{L}^{-1}$ obtained in the present work.

From comparison of the avoidance responses to copper observed in the present work and the sublethal effects described elsewhere, it could be concluded that avoidance tends to occur in a short time and at environmentally relevant concentrations. Drummond et al. (1973) found that changes in the locomotor activity and feeding behavior of Salvelinus fontinalis appeared after $24 \mathrm{~h}$ exposure to copper at $15 \mu \mathrm{g} \cdot \mathrm{L}^{-1}$. Vieira et al. (2009) reported that Pomatoschistus microps exposed to copper at $50 \mu \mathrm{g} \cdot \mathrm{L}^{-1}$ for $96 \mathrm{~h}$ suffered disruption of cholinergic function (due to AChE inhibition), decreased detoxification capability (due to EROD inhibition), additional energetic demands to face chemical stress, and oxidative stress and damage, which decreased the swimming performance of the fish. In another study, exposure of Pimephales promelas to copper at $45 \mu \mathrm{g} \cdot \mathrm{L}^{-1}$ for 21 days caused reductions in the number and size of eggs (Driessnack et al., 2017).

\subsection{Avoidance response to a copper gradient: interspecific interactions}

The interaction of the species caused different patterns of avoidance response in the multispecific copper gradient test. In the absence of $P$. reticulata, the avoidance response of $D$. rerio was more intense than when both species were present together in the system. The guppies clearly influenced the dispersion pattern of the zebrafish, which moved towards previously avoided copper concentrations. This could have been related to an effect of copper on the aggression/contention behavior of $D$. rerio, which decreased in the presence of $P$. reticulata. It is also possible that $P$. reticulata displaced $D$. rerio to a more contaminated zone because the former is naturally more aggressive. Other studies have highlighted the effects of contaminants on the behavior of fish. When the fish Gasterosteus aculeatus was exposed to the hormone estradiol, control males increased their aggressive response to a live male conspecific over time, while males exposed to ethinyl estradiol decreased their aggressive response (Bell, 2001). Alyan (2013) exposed males of Betta splendens to the pesticide methyl parathion for up to $24 \mathrm{~h}$. After exposure, the males became less aggressive towards the conspecific, according to analyses of the frequency and duration of opercular erection. McCormick et al. (2013) evaluated the effect of alteration of the $\mathrm{pH}$ of water by an increase of $\mathrm{CO}_{2}$ concentration on the relation between the two fish species Pomacentrus amboinensis and P. moluccensis. Field experiments showed that elevated $\mathrm{CO}_{2}$ changes the pattern of aggression between the two species, hence altering the processes that shape communities and ecosystems. Due either to a reduction in the territorial fighting ability of $D$. rerio when exposed to copper, or to increased aggressiveness of $P$. reticulata, the present results showed that under a contamination scenario with a copper gradient, the guppies occupied the less contaminated zones and displaced the zebrafish to harsher environments. Although the avoidance response is important, the presence of other species with which there is some degree of competitive interaction may cause a species to be displaced (hypothesis based on the effect of $P$. reticulata on the displacement of $D$. rerio) or to lose the ability to compete (hypothesis based on the effect of copper on the displacement of $D$. rerio).

\section{Conclusions}

In the monospecific tests, both species ( $P$. reticulata and $D$. rerio) were able to detect copper and move to a less contaminated area. In the multispecific tests, even in the presence of previously avoidable copper concentrations, the avoidance response of $D$. rerio was affected by the presence of $P$. reticulata. This study shows the importance of understanding the interactions among different fish species in contaminated areas and the way that one species can affect another species, in order to be able to predict the avoidance behavior likely to occur in polluted environments.

\section{Acknowledgments}

The authors are grateful to the Ecology Department of the Institute of Biosciences, University of São Paulo (Brazil). Financial support for this work was provided by FAPESP (Fundação de Amparo à Pesquisa do Estado de São Paulo; grant \#14/22581-8). Scholarships were provided by CAPES (Coordenação de Aperfeiçoamento de Pessoal de Nível Superior) to D.C.V.R. Silva and R.J. Marassi. We also thank the São Paulo Agency of Agribusiness and Technology (Pindamonhangaba, Brazil). C.V.M. Araújo is grateful to the Spanish Ministry of Economy and Competitiveness for a Juan de la Cierva contract (IJCI-2014-19318).

\section{Appendix A. Supplementary data}

Supplementary data to this article can be found online at https://doi. org/10.1016/j.scitotenv.2018.06.127.

\section{References}

Abdel-Moneim, A., Moreira-Santos, M., Ribeiro, R., 2015. A short-term sublethal toxicity assay with zebra fish based on preying rate and its integration with mortality. Chemosphere 120:568-574. https://doi.org/10.1016/j.chemosphere.2014.09.083.

Acosta, S., Maria, N., Altenhofen, S., Dornelles, M., Gomes, P., Bianchini, A., Denise, C. Souza, R., Luiz, A., 2016. Copper at low levels impairs memory of adult zebra fish (Danio rerio) and affects swimming performance of larvae. Comp. Biochem. Physiol. Part C 185-186:122-130. https://doi.org/10.1016/j.cbpc.2016.03.008.

Alyan, S., 2013. Methyl parathion reduces aggressive behaviour of male Betta splendens. Fresenius Environ. Bull. 22, 3103-3105.

APHA - American Public Health Association, 2012. Standard Methods for Examination of Water and Waste Water. 22nd ed. Washington, DC.

Araújo, C.V.M., Cedeño-Macías, L.A., Vera-Vera, V.C., Salvatierra, D., Rodríguez, E.N.V., Zambrano, U., Kuri, S., 2015. Predicting the effects of copper on local population decline of 2 marine organisms, cobia fish and whiteleg shrimp, based on avoidance response. Environ. Toxicol. Chem. 35:405-410. https://doi.org/10.1002/etc.3192.

Araújo, C.V.M., Moreira-Santos, M., Ribeiro, R., 2016. Active and passive spatial avoidance by aquatic organisms from environmental stressors: a complementary perspective and a critical review. Environ. Int. 92-93:405-415. https://doi.org/10.1016/j. envint.2016.04.031.

Araújo, C.V.M., Rodríguez, E.N.V., Salvatierra, D., Cedeño-Macias, L.A., Vera-Vera, V.C., Moreira-Santos, M., Ribeiro, R., 2016. Attractiveness of food and avoidance from contamination as conflicting stimuli to habitat selection by fish. Chemosphere 163: 177-183. https://doi.org/10.1016/j.chemosphere.2016.08.029.

Araújo, C.V.M., Shinn, C., Mendes, L.B., Delello-Schneider, D., Sanchez, A.L., Espíndola, E.L.G., 2014. Avoidance response of Danio rerio to a fungicide in a linear contamination gradient. Sci. Total Environ. 484:36-42. https://doi.org/10.1016/j. scitotenv.2014.03.037.

Araújo, C.V.M., Shinn, C., Moreira-Santos, M., Lopes, I., Espíndola, E.L.G., Ribeiro, R., 2014. Cooper-driven avoidance and mortality in temperate and tropical tadpoles. Aquat. Toxicol. 146:70-75. https://doi.org/10.1016/j.aquatox.2013.10.030. 
Araújo, C.V.M., Silva, D.C.V.R., Gomes, L.E.T., Acayaba, R.D., Montagner, C.C., MoreiraSantos, M., Ribeiro, R., Pompêo, M.L.M., 2018. Habitat fragmentation caused by contaminants: atrazine as a chemical barrier isolating fish populations. Chemosphere 193:24-31. https://doi.org/10.1016/j.chemosphere.2017.11.014.

Begon, M., Townsend, C.R., Harper, J.L., 2007. Ecology - From Individuals to Ecosystems. 4th ed. Artmed.

Bell, A.M., 2001. Effects of an endocrine disrupter on courtship and aggressive behaviour of male three-spined stickleback, Gasterosteus aculeatus. Anim. Behav. 62:775-780. https://doi.org/10.1006/anbe.2001.1824.

Buske, C., Gerlai, R., 2011. Shoaling develops with age in zebrafish (Danio rerio). Prog. Neuro-Psychopharmacol. Biol. Psychiatry 35:1409-1415. https://doi.org/10.1016/j. pnpbp.2010.09.003.

Chapman, D.W., 1966. Food and space as regulators of salmonid populations in streams Am. Nat. 100, 345-357.

Chapman, B.B., Ashley, J.W.W., Krause, J., 2008. Schooling and learning: early social environment predicts social learning ability in the guppy, Poecilia reticulata. Anim. Behav. 76:923-929. https://doi.org/10.1016/j.anbehav.2008.03.022.

Chatterjee, S., Datta, S., Das, T.K., Veer, V., Mishra, D., Chakraborty, A., Chattopadhyay, B. Datta, S., Mukhopadhyay, S.K., Gupta, D.K., 2016. Metal accumulation and metallothionein induction in Oreochromis niloticus. Ecol. Eng. 90:405-416. https://doi.org/ 10.1016/j.ecoleng.2016.01.049.

Clotfelter, E.D., Rodriguez, A.C., 2006. Behavioral changes in fish exposed to phytoestrogens. Environ. Pollut. 144:833-839. https://doi.org/10.1016/j. envpol.2006.02.007.

Craig, P.M., Wood, C.M., McClelland, G.B., 2010. Water chemistry alters gene expression and physiological end points of chronic waterborne copper exposure in zebrafish, Danio rerio. Environ. Sci. Technol. 44:2156-2162. https://doi.org/10.1021/es902995q

Driessnack, M.K., Jamwal, A., Niyogi, S., 2017. Effects of chronic exposure to waterborne copper and nickel in binary mixture on tissue-specific metal accumulation and reproduction in fathead minnow (Pimephales promelas). Chemosphere 185:964-974. https://doi.org/10.1016/j.chemosphere.2017.07.100.

Drummond, R.A., Spoor, W.A., Olson, G.F., 1973. Some short-term indicators of subletha effects of copper on brook trout, Saluelinus fontinalis. J. Fish. Res. Board Can. 30: 698-701. https://doi.org/10.1139/f73-122.

Dunlop, R., Millsopp, S., Laming, P., 2006. Avoidance learning in goldfish (Carassius auratus) and trout (Oncorhynchus mykiss) and implications for pain perception. Appl. Anim. Behav. Sci. 97:255-271. https://doi.org/10.1016/j.applanim.2005.06.018.

Elkins, D., Grossman, G.D., 2014. Invasive rainbow trout affect habitat use, feeding efficiency, and spatial organization of warpaint shiners. Biol. Invasions 16:919-933. https://doi.org/10.1007/s10530-013-0548-2.

Fausch, K.D., White, R.J., 1981. Competition between brook trout (Salvelinus fontinalis) and brown trout (Salmo trutta) for positions in a Michigan stream. Can. J. Fish Aquat. Sci. 38:1220-1227. https://doi.org/10.1139/f81-164.

Folmar, L.C., 1976. Overt avoidance reaction of rainbow trout fry to nine herbicides. Environ. Contam. 15, 509-514

Fost, B.A., Ferreri, C.P., 2015. pH preference and avoidance responses of adult brook trout Salvelinus fontinalis and brown trout Salmo trutta. J. Fish Biol. 86:952-966. https://doi. org/10.1111/jfb. 12610 .

Fu, Z., Wu, F., Chen, L., Xu, B., Feng, C., Bai, Y., Liao, H., Sun, S., Giesy, J.P., Guo, W., 2016 Copper and zinc, but not other priority toxic metals, pose risks to native aquatic species in a large urban lake in Eastern China. Environ. Pollut. 219:1069-1076. https:// doi.org/10.1016/j.envpol.2016.09.007.

Gimeno, E., Quera, V., Beltran, F.S., Dolado, R., 2016. Differences in shoaling behavior in two species of freshwater fish (Danio rerio and Hyphessobrycon herbertaxelrodi). J. Comp. Psychol. 130:358-368. https://doi.org/10.1037/com0000041.

Gunn, J.M., Noakes, D.L.G., 1986. Avoidance of low pH and elevated Al concentrations by brook charr (Salvelinus fontinalis) alevins in laboratory tests. Water Air Soil Pollut. 30: 497-503. https://doi.org/10.1007/BF00305218.
Laurane, W., Pauline, L., Mathieu, D., 2017. Habitat selection and reproduction of newts in networks of fish and fishless aquatic patches. Anim. Behav. 123:107-115. https://doi. org/10.1016/j.anbehav.2016.10.027.

Lingaraja, T., Sasi Bhushana Rao, P., Venugopalan, V.K., 1979. DDT induced ethological changes in estuarine fish. Environ. Biol. Fish 4:83-88. https://doi.org/10.1007/ BF00005932.

Lopes, I., Baird, D.J., Ribeiro, R., 2004. Avoidance of copper contamination by field population of Daphnia longispina. Environ. Toxicol. Chem. 23:1702-1708. https://doi.org/ 10.1897/03-231.

Martinez-Haro, M., Beiras, R., Bellas, J., Capela, R., Pedro, J., Lopes, I., Moreira-Santos, M., Reis-Henriques, A.M., Ribeiro, R., Santos, M.M., Carlos, J., 2015. A review on the ecological quality status assessment in aquatic systems using community based indicators and ecotoxicological tools: what might be the added value of their combination? Ecol. Indic. 48:8-16. https://doi.org/10.1016/j.ecolind.2014.07.024.

McCormick, M.I., Watson, S., Munday, P.L., 2013. Ocean acidification reverses competition for space as habitats degrade. Sci. Rep. 2:24-26. https://doi.org/10.1038/srep03280.

McIntyre, J.K., Baldwin, D.H., Meador, J.P., Scholz, N.L., 2008. Chemosensory deprivation in juvenile coho salmon exposed to dissolved copper under varying water chemistry conditions. Environ. Sci. Technol. 42:1352-1358. https://doi.org/10.1021/es071603e.

Moreira-Santos, M., Donato, C., Lopes, I., Ribeiro, R., 2008. Avoidance tests with small fish: determination of the median avoidance concentration and of the lowest-observedeffect gradient. Environ. Toxicol. Chem. 27:1576-1582. https://doi.org/10.1897/07094.

OECD, 2000. OECD guideline for testing of chemicals - fish. Juvenile Growth Test 301, 231-236.

Sakuma, M., 1998. Probrit analysis of preference data. Appl. Entomol. Zool. (3), 339-347.

Saraux, C., Fromentin, J.M., Bigot, J.L., Bourdeix, J.H., Morfin, M., Roos, D., 2014. Spatial structure and distribution of small pelagic fish in the northwestern Mediterranean Sea. PLoS One 9 (11), e111211. https://doi.org/10.1371/journal.pone.0111211.

Scherer, E., Mcnicol, R.E., 1998. Preference-avoidance responses of lake whitefish (Coregonus clupeaformis) to competing gradients of light and copper, lead, and zinc. Water Res. 32:924-929. https://doi.org/10.1016/S0043-1354(97)00299-6.

Scherer, A.E., Smee, D.L., 2016. A review of predator diet effects on prey defensive responses. Chemoecology 26:83-100. https://doi.org/10.1007/s00049-016-0208-y.

Seghers, B.H., Magurran, A.E., 1995. Population differences in the schooling behaviour of the Trinidad guppy, Poecilia reticulata: adaptation or constraint? Can. J. Zool. 73: 1100-1105. https://doi.org/10.1139/z95-131.

Silva, D.C.V.R., Araújo, C.V.M., França, F.M., Neto, M.B., Paiva, T.C.B., Silva, F.T., Pompêo, M.L.M., 2018. Bisphenol risk in fish exposed to a contamination gradient: triggering of spatial avoidance. Aquat. Toxicol. 197:1-6. https://doi.org/10.1016/j. aquatox.2018.01.016.

Silva, D.C.V.R., Araújo, C.V.M., Julio, C.L.D., Neto, M.B., Silva, F.T., Paiva, T.C.B., Pompêo, M.L.M., 2017. Potential effects of triclosan on spatial displacement and local population decline of the fish Poecilia reticulata using a non-forced system. Chemosphere 184:329-336. https://doi.org/10.1016/j.chemosphere.2017.06.002.

Stehfest, K.M., Carter, C.G., McAllister, J.D., Ross, J.D., Semmens, J.M., 2017. Response of Atlantic salmon Salmo salar to temperature and dissolved oxygen extremes established using animal-borne environmental sensors. Sci. Rep. 7 (4545). https://doi.org/ 10.1038/s41598-017-04806-2.

Vasconcelos, A.M., Daam, M.A., dos Santos, L.R., Sanches, A.L., Araújo, C.V.M., Espíndola, E.L., 2016. Acute and chronic sensitivity, avoidance behavior and sensitive life stages of bullfrog tadpoles exposed to the biopesticide abamectin. Ecotoxicology 25 (3): 500-509. https://doi.org/10.1007/s10646-015-1608-4.

Vieira, LR., Gravato, C., Soares, A.M.V.M., Morgado, F., Guilhermino, L, 2009. Acute effects of copper and mercury on the estuarine fish Pomatoschistus microps: linking biomarkers to behaviour. Chemosphere 76:1416-1427. https://doi.org/10.1016/j. chemosphere.2009.06.005. 